Document downloaded from:

http://hdl.handle.net/10251/158494

This paper must be cited as:

Broatch, A.; Bermúdez, V.; Serrano, J.; Tabet, R.; Gómez, J.; Bender, S. (2019). Analysis of Passenger Car Turbocharged Diesel Engines Performance When Tested at Altitude and of the Altitude Simulator Device Used. Journal of Engineering for Gas Turbines and Power. 141(8):1-9. https://doi.org/10.1115/1.4043395

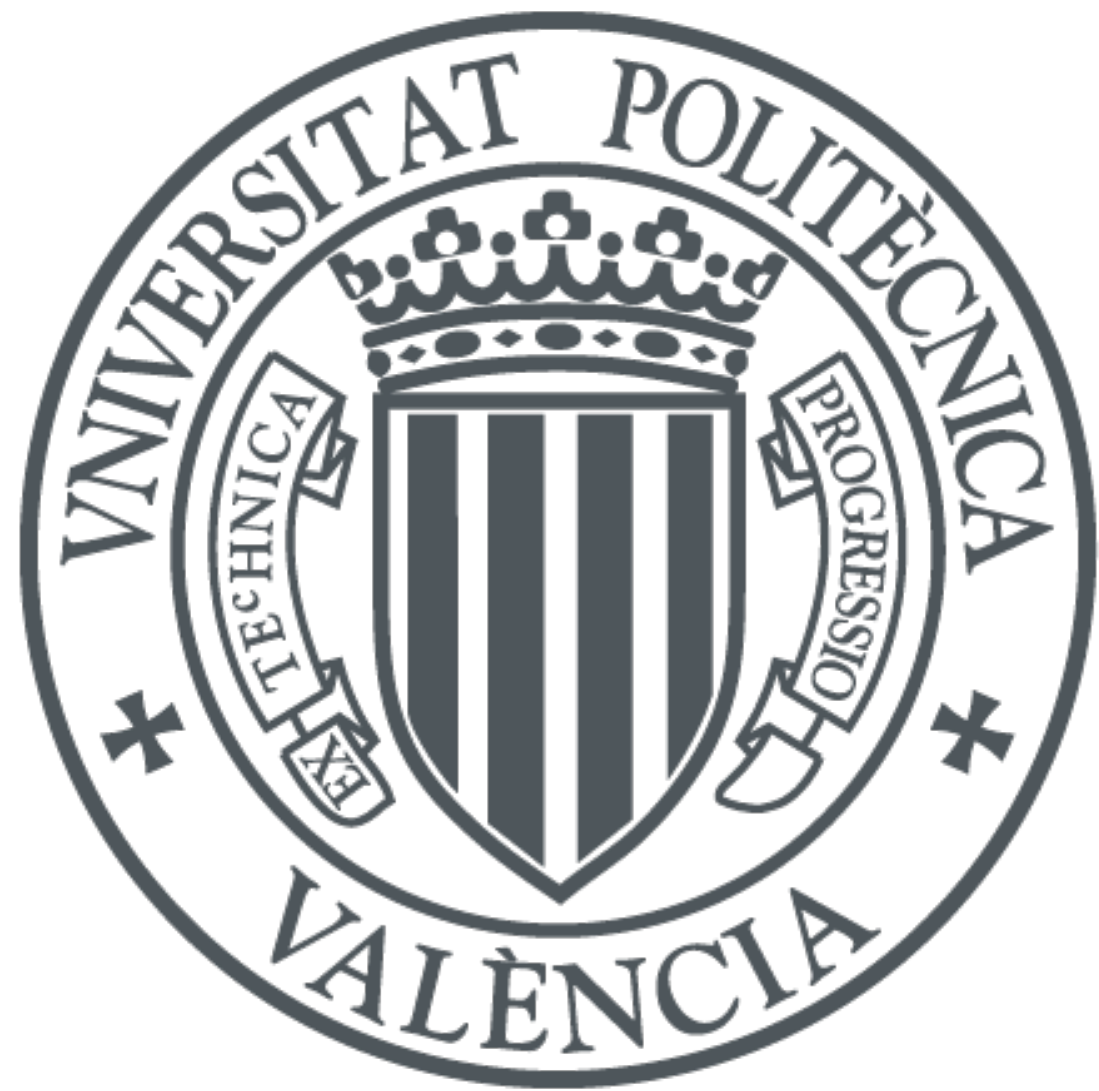

The final publication is available at https://doi.org/10.1115/1.4043395

Copyright ASME International

Additional Information 


\section{Analysis of Passenger Car Turbocharged Diesel Engines Performance When Tested at Altitude and of the Altitude Simulator Device Used}

\author{
Prof. Alberto Broatch ${ }^{1}$ \\ Universitat Politècnica de València \\ Camino de Vera s/n, 46022 Valencia, Spain \\ abroatch@mot.upv.es \\ Prof. Jose Ramón Serrano \\ Universitat Politècnica de València \\ Camino de Vera s/n, 46022 Valencia, Spain \\ jrserran@mot.upv.es \\ Dr. Javier Gómez \\ HORIBA Europe Gmbh \\ Landwehrstrasse 55, 64293 Darmstadt, Germany \\ javier.gomez@horiba.com
}

Prof. Vicente Bermúdez

Universitat Politècnica de València

Camino de Vera s/n, 46022 Valencia, Spain

bermudez@mot.upv.es

\author{
Mr. Roberto Tabet \\ Universitat Politècnica de València \\ Camino de Vera s/n, 46022 Valencia, Spain \\ rotaal@mot.upv.es \\ Dr. Stefan Bender \\ HORIBA Europe Gmbh \\ Landwehrstrasse 55, 64293 Darmstadt, Germany \\ Stefan.Bender@horiba.com
}

performance and emissions of the studied engine with both types of testing equipments for altitude simulation.

\section{INTRODUCTION}

In the new Euro6 [1], which regulates the homologation process for automotive engines, a more realistic driving cycle than the New European Driving Cycle (NEDC) is included. This is the World-wide harmonized Light duty Test Cycle (WLTC). In addition, real driving test in extended conditions, i.e.: altitude up to 1300 meters over sea level and $-7^{\circ} \mathrm{C}$, are also included.

In altitude conditions the air density decreases [2] what affects the performance and emissions, due to the appearance of some particular phenomena that lead to changes in the engine behavior. One of them is the generation of smaller fuel drop size what lowers the coalescence [3, 4] and then decrease the jet-to-wall impingement [5] as the fuel evaporates and mix with the air better inside the combustion chamber. However, the lower air density decreases the spray angle thus increasing the penetration of the fuel spray [5]. Also the higher backpressure generated by the turbine to keep performance by means of maintaining boost pressure produce backflows in the exhaust valves that increases the production of pollutants and soot. 
In order to study the altitude factor and find solutions to the phenomena associated, in the early engine calibration phases, the hypobaric chambers have been used as the standard tool. The real driving tests are only used in the final part of the calibration. The hypobaric chambers have been an option due to the high costs and low repeatability of real driving tests. Nevertheless, hypobaric chambers have some important drawbacks. They are very expensive and voluminous structures and need of extensive planning previous to construction what causes that this type of chambers are very exceptional in the engine development centers [6]. Moreover, the human body cannot withstand repeated pressure changes [7] so operating inside hypobaric chambers entails a serious health risk what limit the number of testing hours in a chassis dyno test cell.

To avoid the drawbacks of hypobaric chambers, devices in which the altitude is only generated inside the engine intake and exhaust while the rest of the engine is at room pressure has been developed, they are called altitude simulators (AS). An example could be the one presented by Testa et al. [8], an AS that changes the pressure by means of two root compressors, upstream and downstream of the engine connection, to reproduce altitude conditions. To generate vacuum the upstream volumetric compressor throttles the installation acting like a valve while the downstream compressor is in charge of moving the flow. On the other hand, to generate overpressure they exchange their functions. Additionally, to control temperature and humidity an air conditioning unit is connected upstream the installation. However, in public literature has not been found comparisons with hypobaric chambers or real driving tests. In the literature can be found also the AS HORIBA MEDAS [9, 10, 11]. This AS has already been used to analyze the performance and emissions of an engine in dynamic operation while performing an NEDC cycle at 3 different altitudes. The conclusions have been reported at [12].

In this paper, has been analyzed the HORIBA AS behavior, coupled to intake temperature and humidity modifiers, and while generating dynamic altitude conditions with an engine in dynamic operation (load and speed steps). Also, in order to contribute in the validation of the altitude simulators an analysis has been done over the results of a complete engine map in steady state operation at two different altitudes using a standard hypobaric chamber and the AS. A dispersion study on the test bench measurements has been also carried out to help in the understanding of the comparison results.

\section{EQUIPMENT DESCRIPTION}

The equipment used during testing for simulating altitude are a set of new and innovative systems developed by University research institute CMT-Motores Térmicos in partnership with Horiba Europe GmbH, which operating principle is explained in detail in [13] and its design features and performance are discussed in [14].

They have been design specifically for the experimental analysis of engines operation against variable altitude and variable atmospheric conditions. The equipment are conceived to be used at engines laboratories and have been checked against a hypobaric chamber at authors' premises.

They are three systems whose objectives are to control the three main psychrometric variables of the atmosphere: pressure, temperature and humidity. They have been commercially called by HORIBA as: MEDAS (Multifunctional Efficient and Dynamic Altitude Simulator); MTM (MEDAS Temperature Module) and MHM (MEDAS Humidity Module), (1A), (1B) and (1C) of Fig. 1 and will be called here in after as AS (Altitude Simulator), ASTM (Altitude Simulator Temperature Module) and ASHM (Altitude Simulator Humidity Module) respectively.

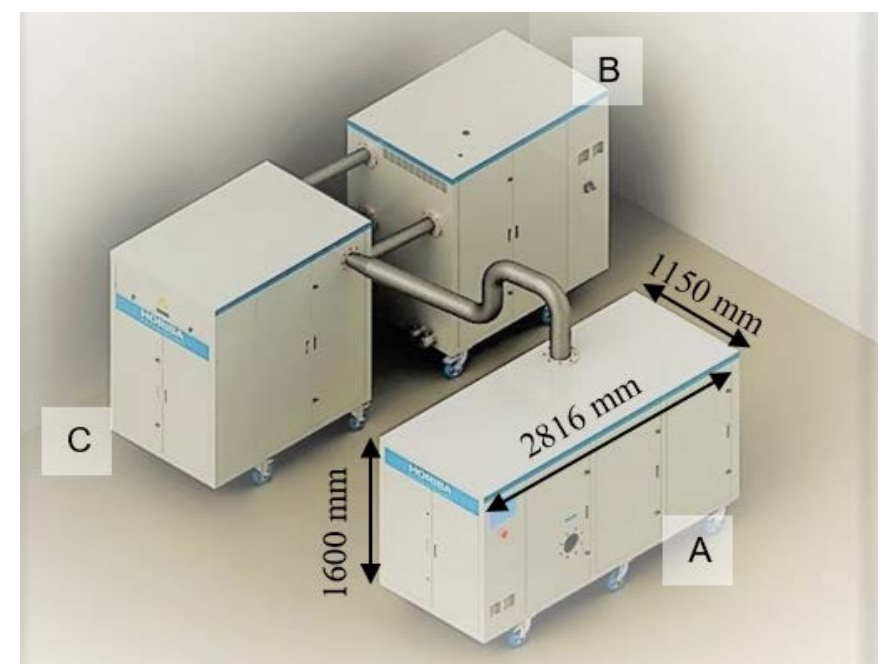

Fig. 1. Atmospheric simulator set: AS [A], ASTM [B], ASHM [C]

The conditioning objective of the combustion air is achieved in the flow within a dilution pipe, at which the engine intake and exhaust are connected; and mainly by means of turbo machinery, heat exchangers and flow control valves. In Fig. 2 a conceptual scheme of the three systems connected together is shown.

Fig. 2 can be explained by following the air flow path through the installation. The installation sucks air through the air filter (1) from Fig. 2 that then goes to a mechanical compressor (2). Downstream is a purging valve (3) that prevents the mechanical compressor of entering into surge zone by opening the way to a discharge duct and thus increasing the mass flow rate through the compressor. Also downstream the mechanical compressor, the control valve (4) controls the temperature in point ' $g$ ' by means of forcing a portion of the flow going through the cooling equipment. Cooling equipment consist of a water-to-air cooler (5), which precools the air, and air-to-glycolic water chiller (6). At (6) finish the cooling process and air plus water condensates go to an inertial separator (7), where the water condensates are separated and removed.

Once the air has been cooled and dried there are two control options: reheat the air to achieve the temperature set point (Dry mode) or moisten it to achieve the humidity set point (Humid mode). On one hand, when Dry mode is active the control valve (9) regulates air flow through the electric heater (8) to regulate 
the temperature at far point 'l'. The control valve (10) is operated in opposition of (9), what facilitates the process of regulating the air passing through (8). During this operation mode the control valves (11) and (12) are fully closed and fully open respectively, bypassing the bubble reactor (13). On the other hand, when Humid mode is activated, the E-heater (8) controls the water temperature inside deposit (13). In Humid mode valve (9) is controlling how much air flow is bypassing (13) in order to fit the humidity level at far point 'l'. In Humid mode valve (10) is fully closed and valve (11) is operating conjugated with (9) for helping in the humidity control process.

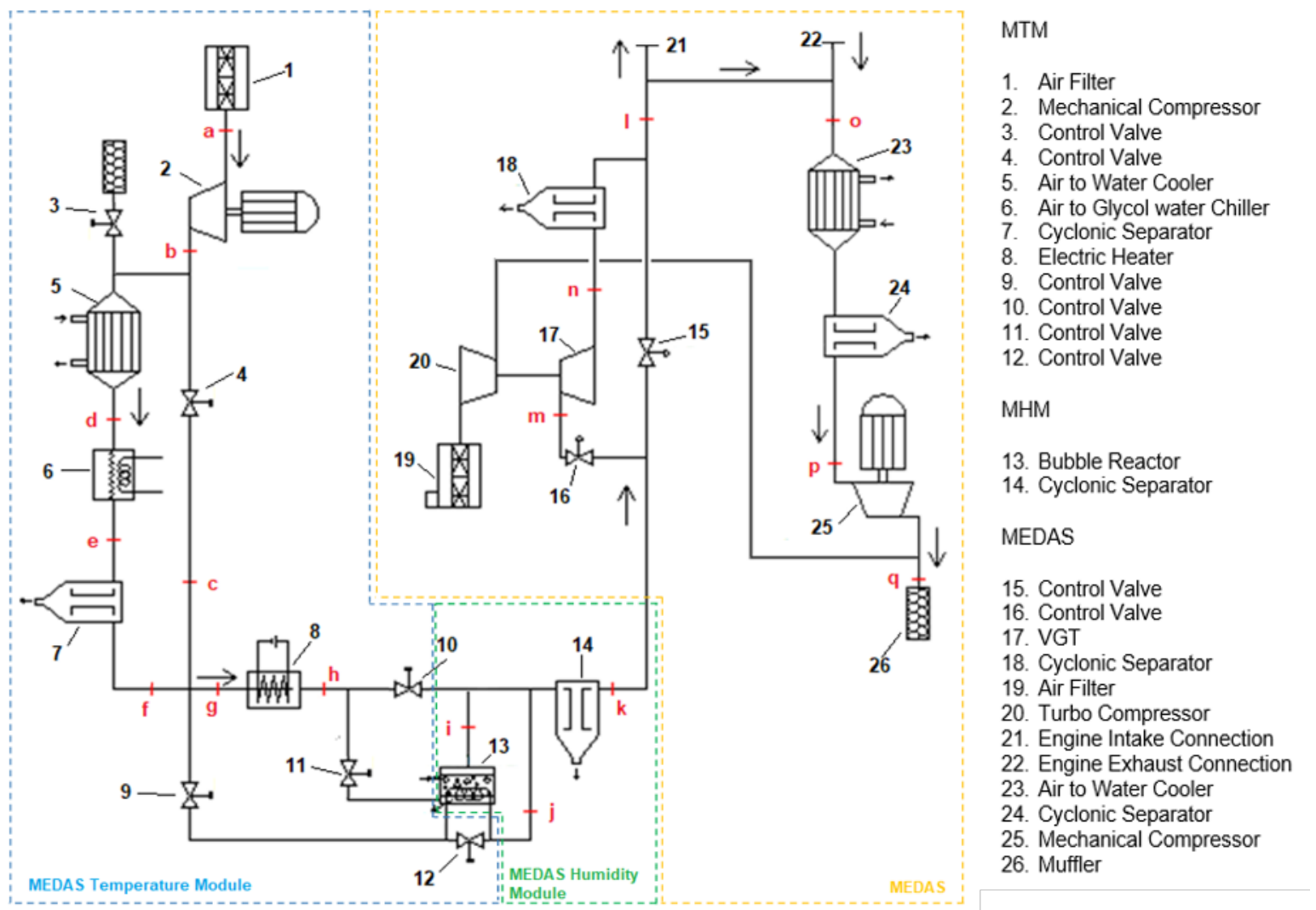

Fig. 1. Atmospheric simulator set. Layout and conceptual scheme.

Valve (12) bypasses an air-to-water heat exchanger inside deposit (13). Valve (12) opens and closes depending on the temperature at point ' $g$ '. Valve (12) closes when the air temperature at ' $g$ ' is higher than the water temperature inside (13), in order to heat the water, and opens in the opposite case. With the ASHM operated in described way is possible to achieve up to $80 \%$ relative humidity at altitudes like $5000 \mathrm{~m}$ and at temperatures as high as $40^{\circ} \mathrm{C}$. High altitude, hot and humid air conditions as described would be physically impossible to achieve in combustion air just injecting water or steam in the air at room conditions as traditionally has been done in CAHUs or other altitude simulators proposed [15]. The reason is that specific humidity required at high altitude and temperature well overcomes $100 \%$ relative humidity at room pressure and room temperature at sea level.

In summary, the desired relative humidity is achieved by mixing a stream of dry air (point ' $j$ ') with another of very moist air (point ' $i$ '). In the case valve (12) is open, dry air can be much colder than hot air and there is the possibility of generating condensates. Condensates can damage the turbomachinery located downstream; this is why there is a cyclonic separator (14) after the mixture of both streams of air. In the case valve (12) is closed, dry and $100 \%$ humid streams are at the same temperature and pressure. Therefore the mass ratio between both streams coincide with the relative humidity of the blended stream.

The air stream pre-treated in the ASTM and ASHM enters AS for the final adjustments in pressure and temperature. After entering AS the air can flow through two paths: an isothermal expansion branch or a cooling branch. In isothermal branch a valve (15) is located to control the pressure at point 'I'. In the cooling path is the valve (16), which regulates the flow through it, thus controlling the temperature in point 'l'; and it is the further expansion in a variable geometry turbine (17) what effectively and instantaneously cools the flow. Furthermore, the blades of (17) regulates to help (15) in controlling the pressure. The VGT is mechanically coupled with a compressor (20), which dissipates the energy extracted from the combustion air flow in 
order to keep it cold. Following, and due to the air cooling in (17), a cyclonic separator (18) is necessary to remove water droplets or ice from the air before engine intake (21).

From the mass flow that circulates through the installation AS, just the quantity needed by the engine flows through (21) towards engine intake filter. Remaining flow passes from point 'l' to point 'o' through the called 'bypass' or 'dilution' pipe. Downstream 'dilution' pipe the by-passed air mixes with the exhaust gases from the engine (22). Afterwards the mix enter into a water-to-air cooler (23) that cools it down to $50{ }^{\circ} \mathrm{C}$; in order to protect the mechanical compressor (25) of overheating. The compressor (25) is in charge of controlling the mass flow rate through the installation sucking the mix of air and exhaust gasses to keep them flowing. Another cyclonic separator (24) is placed at the intake of (25) to protect it from the condensates, generated when cooling the gases, and while required thermal transient to get the desired $50^{\circ} \mathrm{C}$ is completed.

In Fig. 3 results from testing the AS set coupled with an engine are shown. The engine is increasing and then decreasing its load and speed in steps. The AS is reproducing atmosphere of driving from Granada up to Prado Llano, at Sierra Nevada road (910 m to $2100 \mathrm{~m}$ ) and then down again at an average velocity of 100 $\mathrm{km} / \mathrm{h}$. Moreover, during this driving test the emulated temperature and relative humidity at engine intake has been kept constant at $25^{\circ} \mathrm{C}$ and $80 \% \mathrm{RH}$ respectively.

If the focus is put on the accuracy of the psychrometric variables control, all three variables are controlled with an error less than $0.5 \%$; defined as the average error with respect to the set point. Also without apparent disturbances in any of them due to the changes in the engine operational point. Instantaneous peak errors are higher but still below $2 \%$. $2 \%$ is defined with respect to full scales of the AS, which are: $7000 \mathrm{~m} ; 55^{\circ} \mathrm{C}$ and 80 gH2O/kgAir, respectively.

It is worth noting that the specific humidity (g_water $/ \mathrm{kg}$ _dry air) is changing, even when the temperature and relative humidity are constant; the reason is pressure variation with altitude. Since specific humidity is what the system really controls, this fact shows the difficulty of controlling constant relative humidity. One must bear on mind that any change in any of the psychrometric variables: pressure, temperature or relative humidity; involves a variation in specific humidity.

Moreover, as shown in Fig. 3, the load and speed changes cause variations in the exhaust gases temperature (point 'o' of Fig. 2). Nevertheless, these engine exhaust temperature dynamics are controlled by the cooler (23), which always keeps the mechanical compressor inlet temperature (point 'p') lower than $50^{\circ} \mathrm{C}$. 

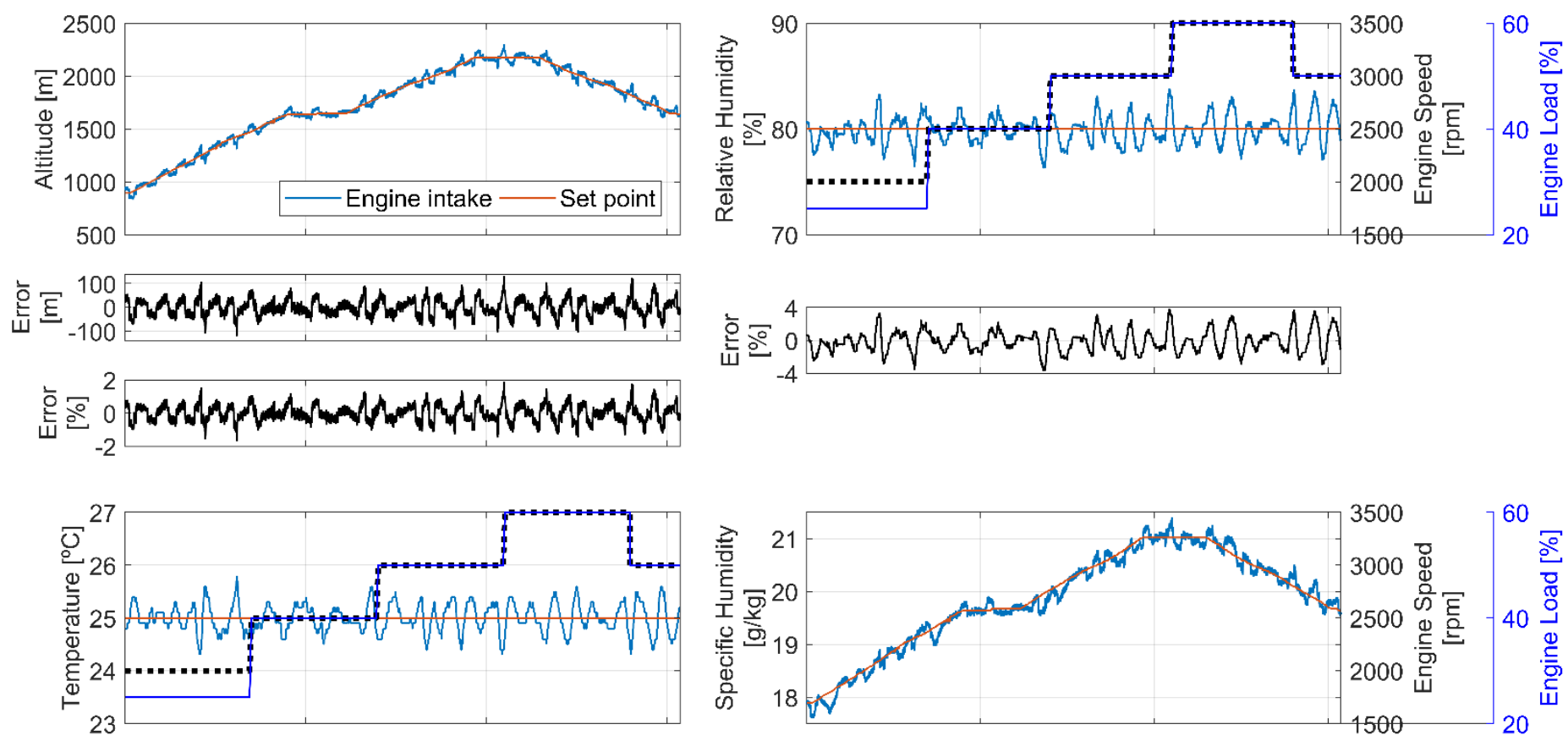

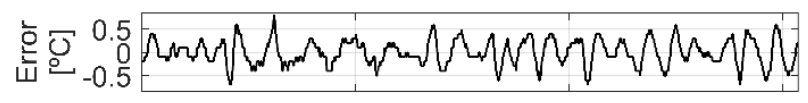
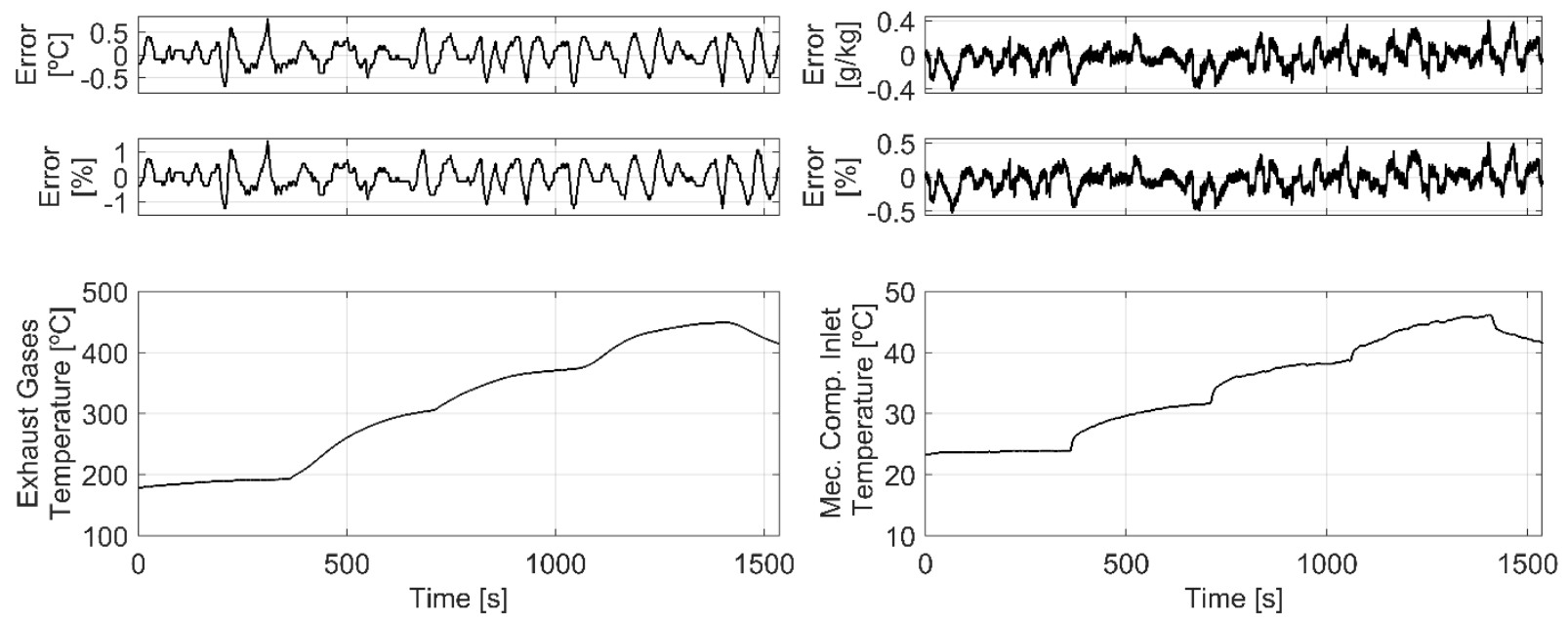

Fig. 2. Dynamic altitude and dynamic engine operation tests.

\section{TEST BENCH DESCRIPTION}

The experiment designed to validate AS system consist of a turbocharged diesel engine coupled to a Foucault current brake. Engine characteristics are listed in Table 1, and both are located inside of a hypobaric and climatic chamber while the AS was placed outside.

A number of steady state engine points was tested at two different altitudes and using two different systems to achieve the altitude conditions. The tested engine speeds, which allow to cover almost the entire operational range of the engine, were: 1500 rpm, $2000 \mathrm{rpm}, 2500 \mathrm{rpm}$ and $3000 \mathrm{rpm}$ and the load levels: 3, 6, 9 bar BMEP and full load. In total 16 points for each combination of altitudes $(1300 \mathrm{~m}$ or $2300 \mathrm{~m})$ and altitude emulation equipment (hypobaric chamber or AS).
When the engine is connected to the AS, the hypobaric chamber is not generating vacuum and the AS is sucking air from the chamber through pipe (A) from Fig. 4. That means all engine external environment is at sea level conditions, while the intake line, connected to pipe (B) of the Fig. 4, and the exhaust line, connected to pipe (C) of the Fig. 4, are at the desired vacuum. Therefore, all engine internal and external surfaces withstand a pressure difference. To avoid collapsing some intake ducts the soft rubber parts had been reinforced. On the other hand, the exhaust lines and air box had been completely sealed to prevent room air insertion from the ambient and loosing vacuum. Also, the ECU pressure sensor had to be either connected to vacuum or modified its value at ECU, due to being at room pressure when simulating altitude with AS. 
The same tests were done with the engine disconnected from AS and simulating the altitude within the hypobaric chamber. In this second case internal and external sides of the engine are at vacuum.
The measurements of emissions in both cases are done between Diesel Oxidation Catalyst (DOC) and Diesel Particulate Filter (DPF), as can be seen in Fig. 4, by means of an HORIBA OBSONE (D) and an AVL 439 Opacimeter (E).

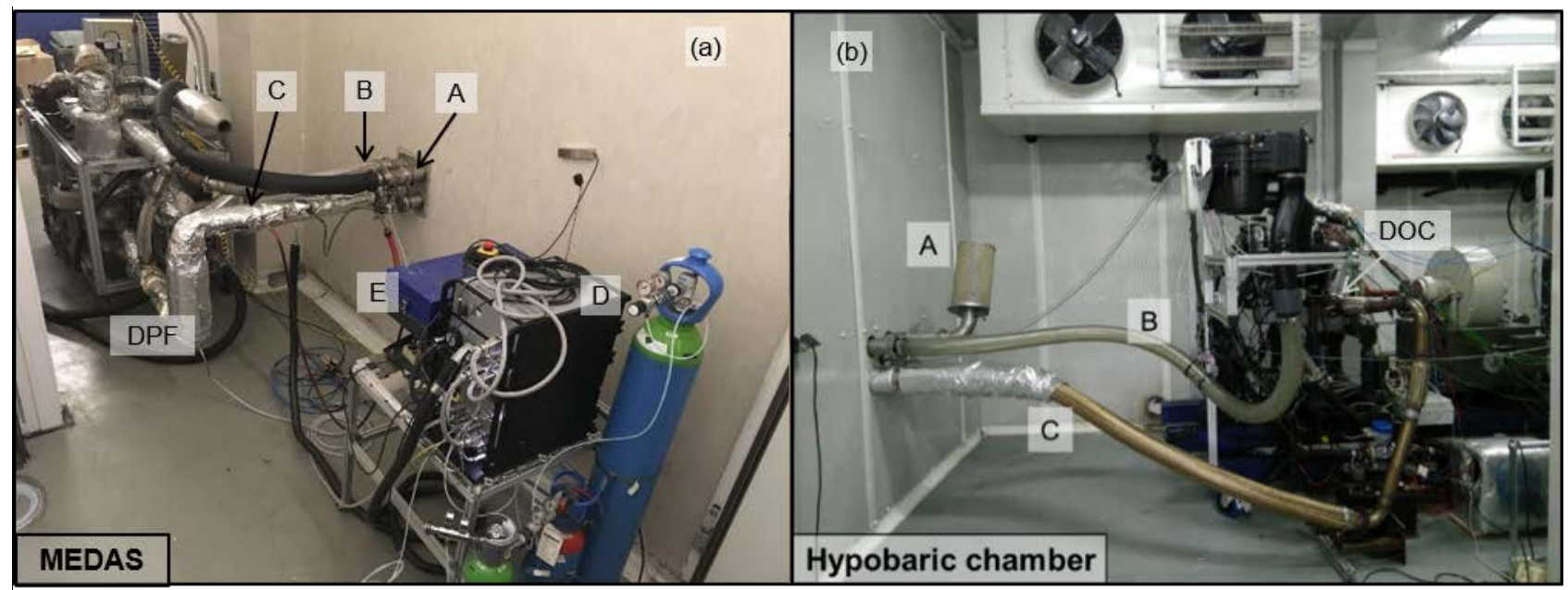

Fig. 3. (a) AS prototype and Emissions measurement equipment. (b) Engine connections inside hypobaric chamber.

Table 1. Engine characteristics.

\begin{tabular}{ll}
\hline Type & HSDI Diesel passenger car engine, Euro V \\
Displacement & $2953 \mathrm{~cm} 3$ \\
Bore & $96 \mathrm{~mm}$ \\
Stroke & $102 \mathrm{~mm}$ \\
Number of cylinders & 4 in line \\
Number of valves & 4 per cylinder \\
Turbocharger model & Variable Geometry Turbine \\
Compression ratio & $17.9: 1$ \\
Maximum power @ speed & $110 \mathrm{~kW} @ 3400$ rpm \\
Maximum torque @ speed & $340 \mathrm{Nm} @ 1500$ rpm \\
Maximum mass flow @ speed & $750 \mathrm{~kg} / \mathrm{h} @ 4500 \mathrm{rpm}$ \& full load \\
EGR type & Cooler, high pressure with intake throttle \\
\hline
\end{tabular}

\section{STANDARD DISPERSION STUDY}

With respect to the turbo compressor operation at altitude, one can see that compressor operates closer to the over speed limit at altitude, as shows charts (a), (b) and (c) in Fig. 5. Not only the turbo speed increases proportionally to the altitude; but also surge limit is reduced in points at low engine speed and full load when altitude increases.

Fig. 5 shows a first analysis of the engine behaviour at the compressor map: colours represent the different engine speed tested; circles and crosses represent points simulated with AS or with hypobaric chamber respectively. It is possible to see that at 1300 meters over sea level the results are equal with altitude simulators; but when going to 2300 meters, and at high speed and load, small differences in the measurements with both systems are shown. Therefore, before continuing with further analysis a dispersion study was done using some engine operational points, shown in Table 2. Each of these points were measured 5 times with every altitude simulation equipment.

In Fig. 6, Fig. 7 and Fig. 8 is depicted the data for most representative engine variables obtained from the test done in the points of Table 2. The data are further differentiated between AS called MEDAS (red markers) and hypobaric chamber called CHAMBER (blue markers)

One can conclude than comparing between both altitude simulators the differences are not significant; being within the measured dispersion with each altitude emulation device. Fig. 6, Fig. 7 and Fig. 8 also show that the dispersion for some variables 
is higher with the AS and for others with the hypobaric chamber. It is worth noting the considerable saving in investment and space and the simplicity of operation if one compares AS like devices with hypobaric chambers [6].

On the other hand, when focusing in the global dispersion and comparing Fig. 6 with Fig. 7 it can be seen that the change of altitude, from $1300 \mathrm{~m}$. to $2300 \mathrm{~m}$. over sea level, produces a great increase in the dispersion of engine variables. Also when comparing Fig. 7 and Fig. 8 some growth of the dispersion with the increase of engine speed is shown.

The effect of the altitude and the engine speed on the measurement dispersion is more clear in pressure (Fig. 6b, Fig. 7b and Fig. 8b) and temperature (Fig. 6c, Fig. 7c and Fig. 8c) than in emissions (Fig. 6a, Fig. 7a and Fig. 8a) due to the high inherent dispersion of the emission measurement systems that sometimes even damps the effect of instabilities in the test bench.
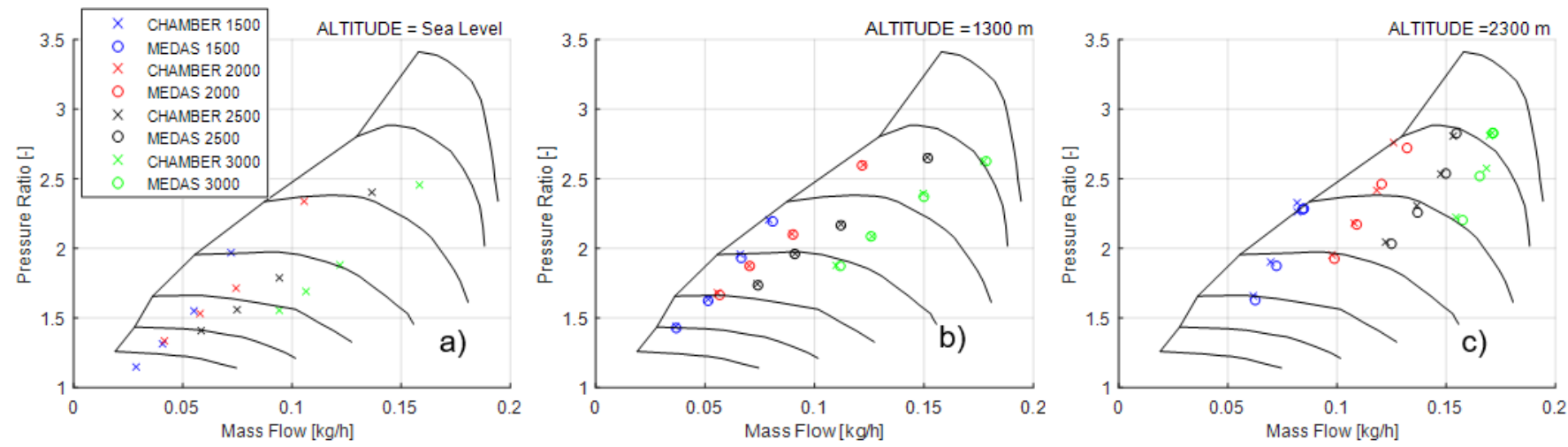

Fig. 4. Engine operative points at turbo compressor map and at different altitudes.

Table 2. Dispersion study points for comparison of AS vs. hypobaric chamber.

\begin{tabular}{ccc} 
Altitude $[\mathrm{m}]$ & Engine Speed $[\mathrm{rpm}]$ & BMEP $[\mathrm{bar}]$ \\
\hline 1300 & 2000 & Full Load \\
2300 & 2500 & Full Load \\
2300 & 3000 & Full Load \\
\hline
\end{tabular}



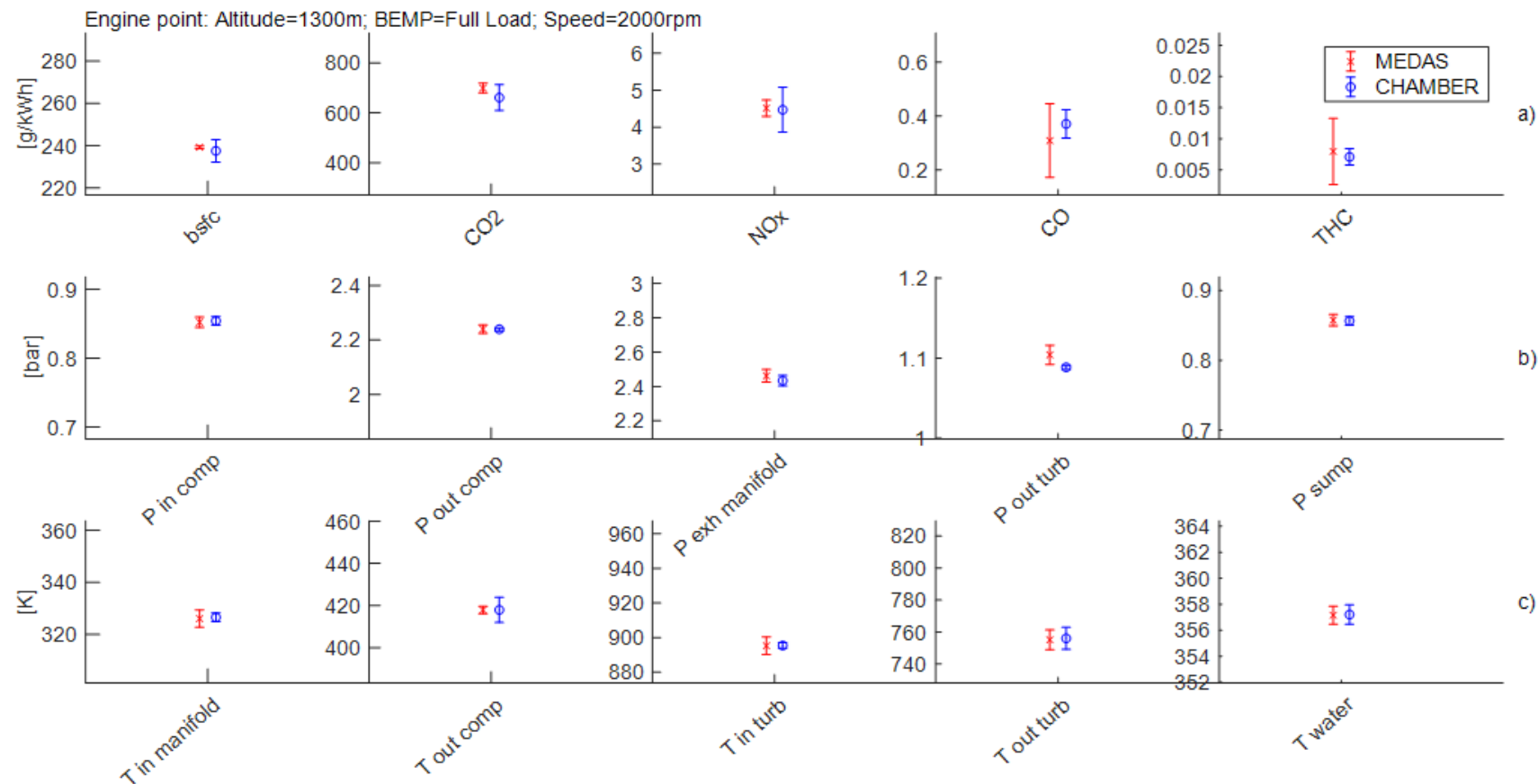

Fig. 5. Dispersion results: at 1300m. 2000 rpm \& full load. Comparison of AS vs hypobaric chamber.

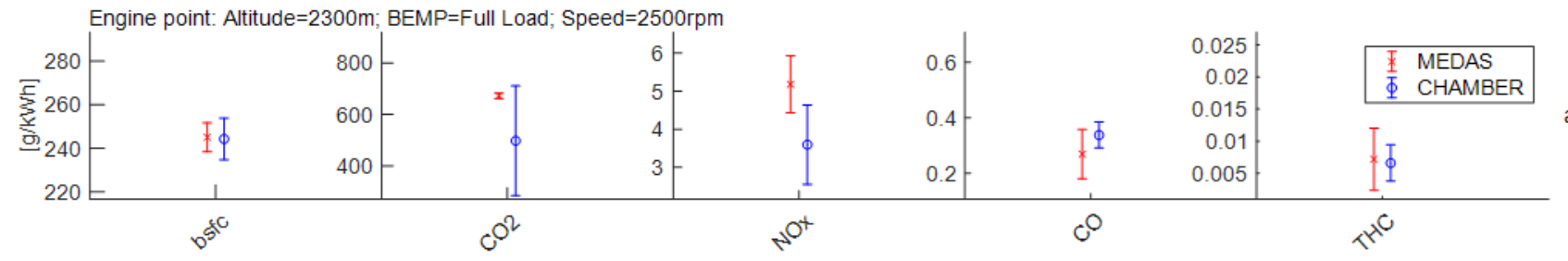

a)

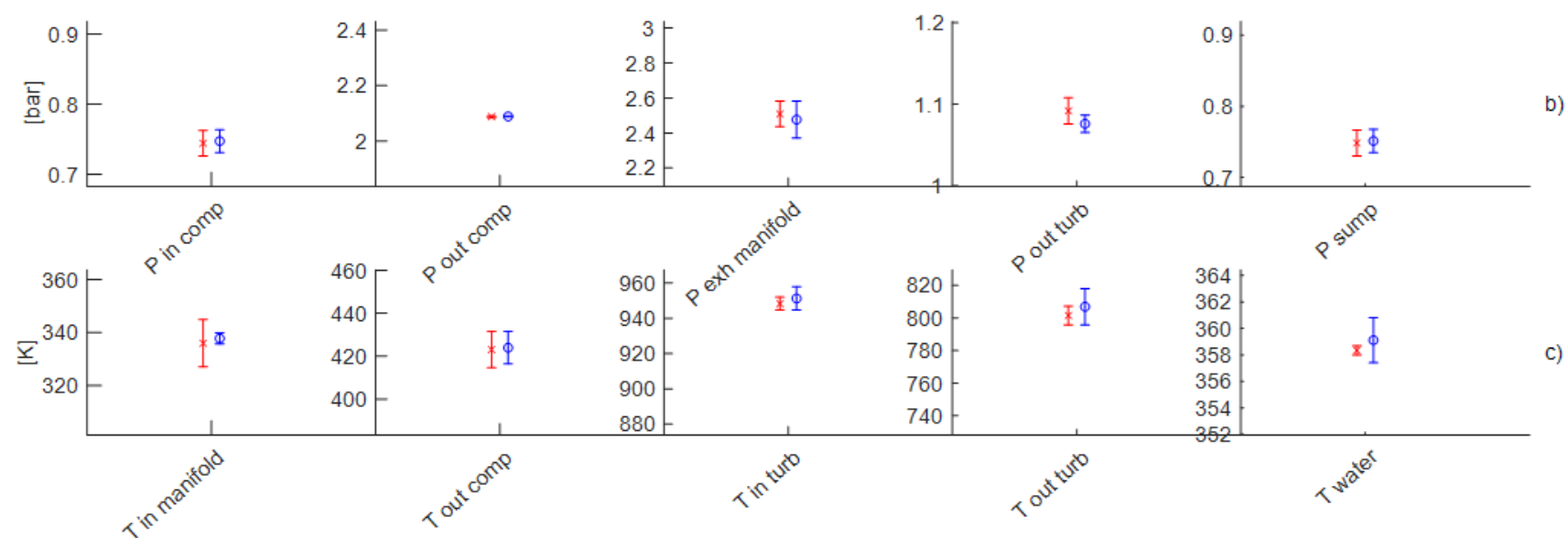

Fig. 6. Dispersion results: at 2300 m. 2500 rpm \& full load. Comparison of AS vs hypobaric chamber. 

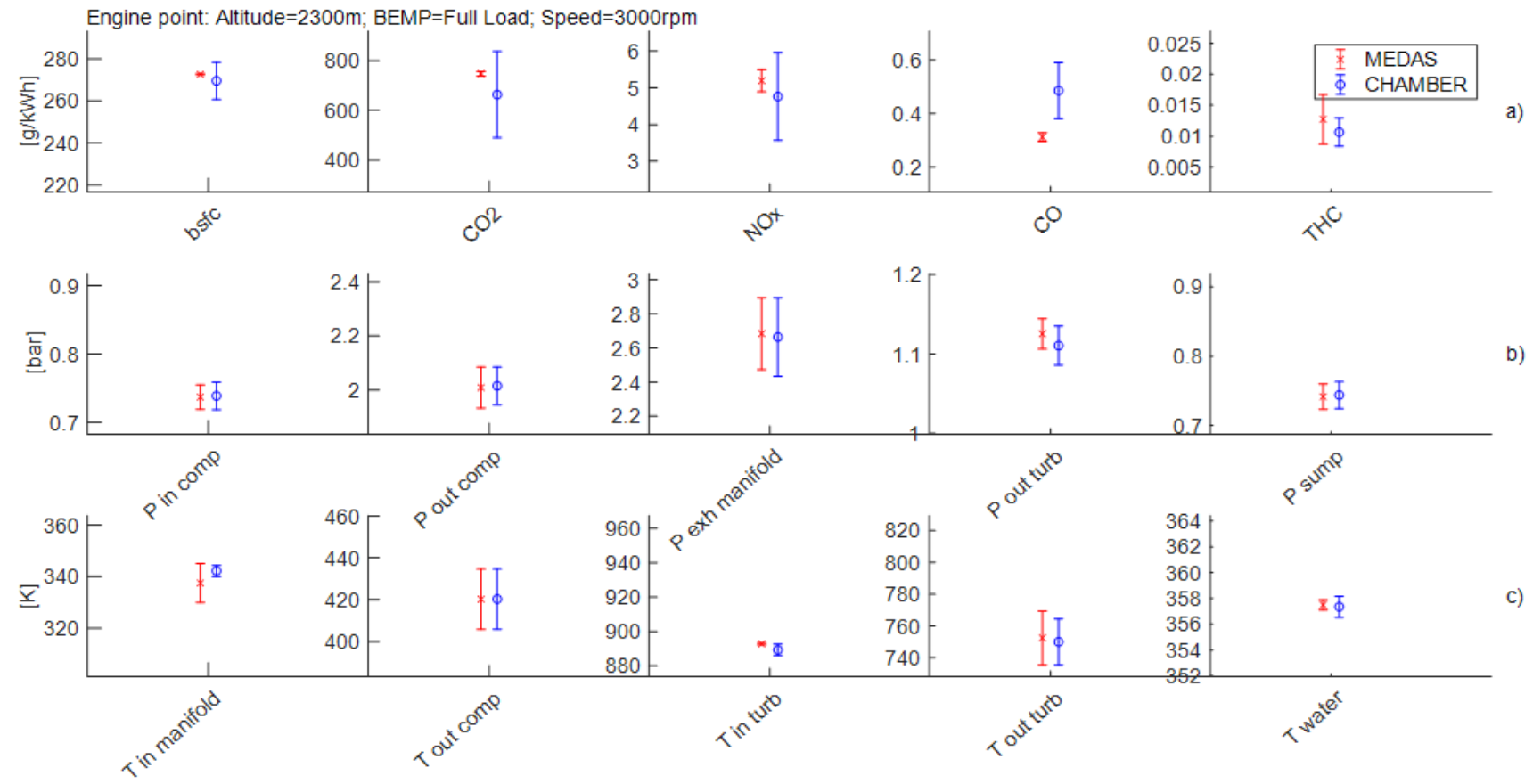

Fig. 7. Dispersion results: at 2300 m. 3000 rpm \& full load. Comparison of AS vs hypobaric chamber.

\section{DISCUSSION OF RESULTS}

Once the dispersion study has been analysed can be said that the differences found in the behaviour of the engine for the three chosen points are mostly due to instabilities in the performance of the engine and dispersion in the measurement devices used in the engine bench. Therefore there is not any significant modification in the engine behaviour at these control points when utilizing an AS for pressurizing intake and exhaust than when operating the engine in a hypobaric chamber.

To do a more detailed analysis of some key engine variables the data has being arranged in a matrix of torque vs speed graphs differentiating both by altitude and by altitude simulator for each engine operational point tested. In the columns one can see the altitude at which the engine has been tested and in the rows the altitude simulator used. Furthermore, the sea level data has been used as a reference and there is not comparison done between simulators for this case.

An example of this characteristic graph arrangement is Fig. 9 in which the position of the EGR control valve is represented. If the three altitudes (sea level, 1300 meters and 2300 meters) are analysed and compared, it can be seen the EGR closing when increasing altitude $(1300 \mathrm{~m})$ ending fully closed at 2300 meters. It is worth noting that the EGR at 1300 meters over sea level is only closed at full load but it is still open for any other load level. Additionally, when comparing the data of the three altitudes a decrease of the maximum torque line can be seen. The drop in torque is visualized easily in the sea level graph in which the maximum torque level achieved in the altitude tests has been represented as a black horizontal line. It decreases for all engine speeds when comparing sea level with 1300 meters of altitude and further decreases at high speeds when comparing 1300 with 2300 meters. Also it should be noted that the decrease in maximum torque is being intentionally caused by the ECU when respecting some engine operative limits, like: the turbo compressor maximum speed; the surge limit and/or the turbine gas inlet temperature.

\section{Turbine inlet}

One of the most sensible stations in the operation of a turbocharged engine is the inlet of the VGT. The conditions of pressure and temperature in this point are going to be affected for example when the atmospheric conditions affect the combustion; when a higher boosting pressure is needed or when the engine makes undesired quantities of EGR.

In Fig. 10 and Fig. 11 the turbine inlet pressure and temperature are shown respectively. Fig. 10 shows that the islands of low pressure, which appear when testing with the hypobaric chamber, are reproduced when testing with the AS. Moreover, the maximum and minimum values for both Fig. 10 and Fig. 11 are the same with any simulating equipment used.

If the effect of the altitude in engine backpressure is analysed, Fig. 10 shows that it is increased at low loads when increasing altitude. The increment is produced by the controlling valve of the turbine that regulates to keep the boost pressure at a desired value. This situation has a clear contrast with the high loads behaviour, in which the backpressure actually drops while going to higher altitudes, due to the decrease of 44 when increasing altitude allows the VGT to keep on a highly open position. 
With respect to the turbine inlet temperature: Fig. 11 shows that at low loads it is increased by the lower (or null) EGR rates done at altitude, which affects the fresh air involved in the combustion. At high loads, on the one hand at 1300 meters the EGR is fully closed, which increases the fresh air that enters the combustion chamber with respect to the sea level reference, thus increasing the temperature. On the other hand at 2300 meters, in spite of the EGR is also closed, the fresh air decreases with respect to 1300 meters data due to the lower density of the atmosphere. The increment in the fuel to air ratio produces a further increment in the temperature after combustion at the same load levels. It is worth noting that excessive turbine inlet temperature is one of the causes that prevents achieving further full load levels of torque at high speeds like $3000 \mathrm{rpm}$.

\section{Brake specific fuel consumption (BSFC)}

Another crucial variable is the BSFC, which is shown in Fig. 12. The engine map of BSFC also has a very similar topography when testing with the AS or with the hypobaric chamber, being the differences between both mainly due to test bench instabilities in the measurement, as concluded in the previous section.

With respects to the effect of the altitude, the BSFC increases when climbing from sea level to 1300 meters in a significant way. This is by the increase of fresh air when closing EGR what means higher heat losses in the combustion chamber and higher pumping losses. But when going up from 1300 to 2300 meters the BSFC is almost the same since there is a decrease in fresh air and a further displacement of operative conditions in the compressor to higher efficiency areas (Fig. 5).
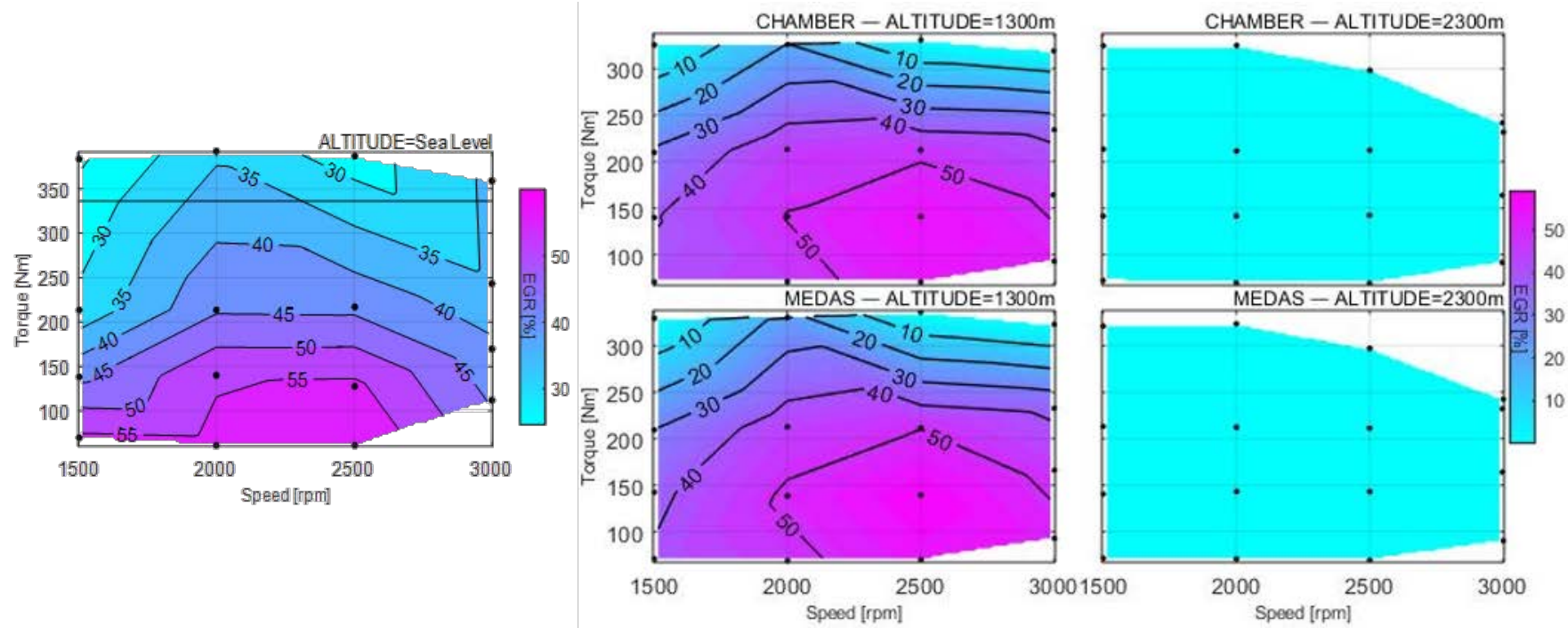

Fig. 8. EGR valve position. Comparison of sea-level vs. altitude. Comparison of AS vs. hypobaric chamber.
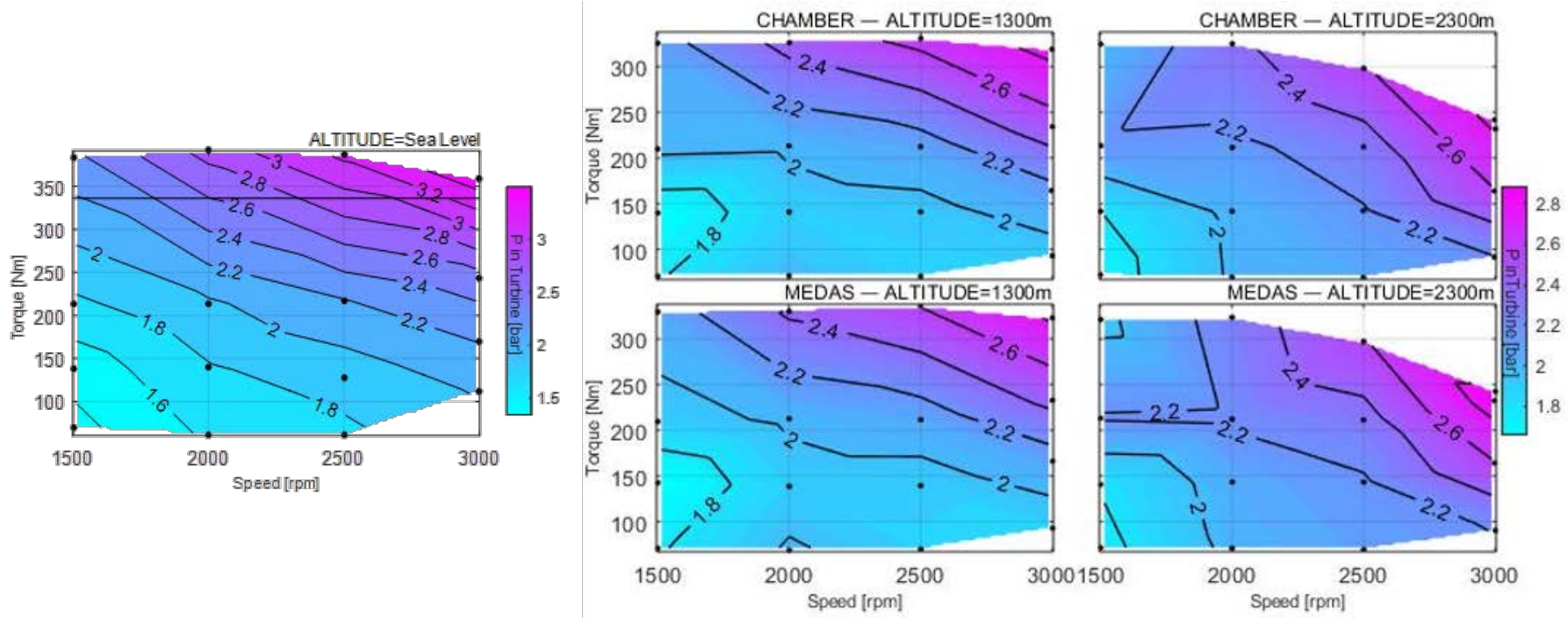

Fig. 9. Turbine inlet pressure. Comparison of sea-level vs. altitude. Comparison of AS vs. hypobaric chamber. 


\section{NOx and THC Emissions}

Analysing emissions variables: NOx and THC are both shown in Fig. 13a and Fig. 13b, respectively. Fig. 13 shows how the topography of the engine map when testing in a full altitude environment is well reproduced, once again, when just connecting intake and exhaust to the AS. Fig. 13 shows that the high and low emission areas are located in the same places in both cases.

When focusing in the effect of the altitude in the production of NOx, in Fig. 13a can be seen how at low loads the generation of NOx is greatly increased when increasing altitude due to the action of EGR which is partially open at 1300 meters over sea level but completely closed at 2300 meters. On the other hand, at high loads the difference decreases with the altitude since the EGR is fully closed in both cases. This behaviour is similar as the one for the turbine inlet temperature since this temperature is a symptom about the generation of NOx.

If the effect of the altitude over THC is now analysed, Fig. 13b shows how the THC emission decreases at low loads with the altitude. This is due to having a higher combustion temperature as a consequence of closing the EGR, thus performing a better combustion that leads to less fuel unburned. At high loads, since the EGR is closed for both altitudes, the combustion temperature is very similar and similar quantity of fuel ends up unburned.

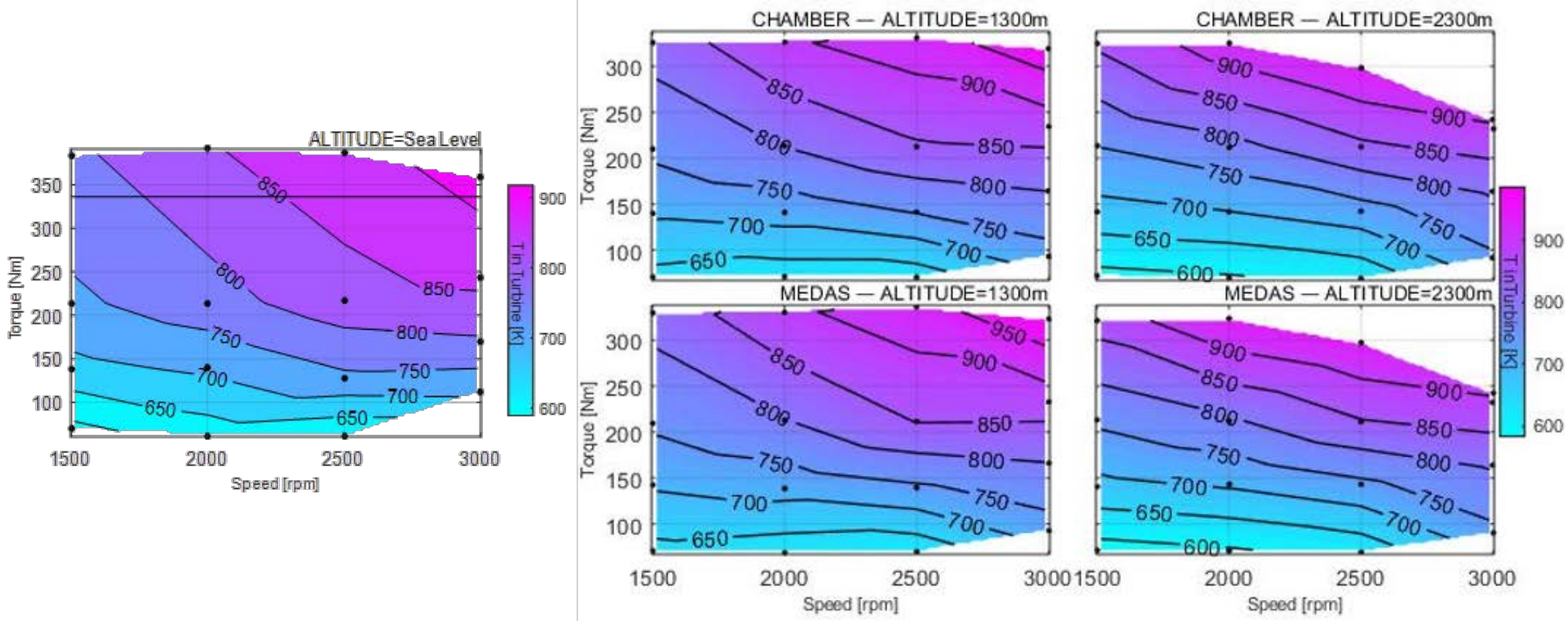

Fig. 10. Turbine inlet temperature. Comparison of sea-level vs. altitude. Comparison of AS vs. hypobaric chamber.
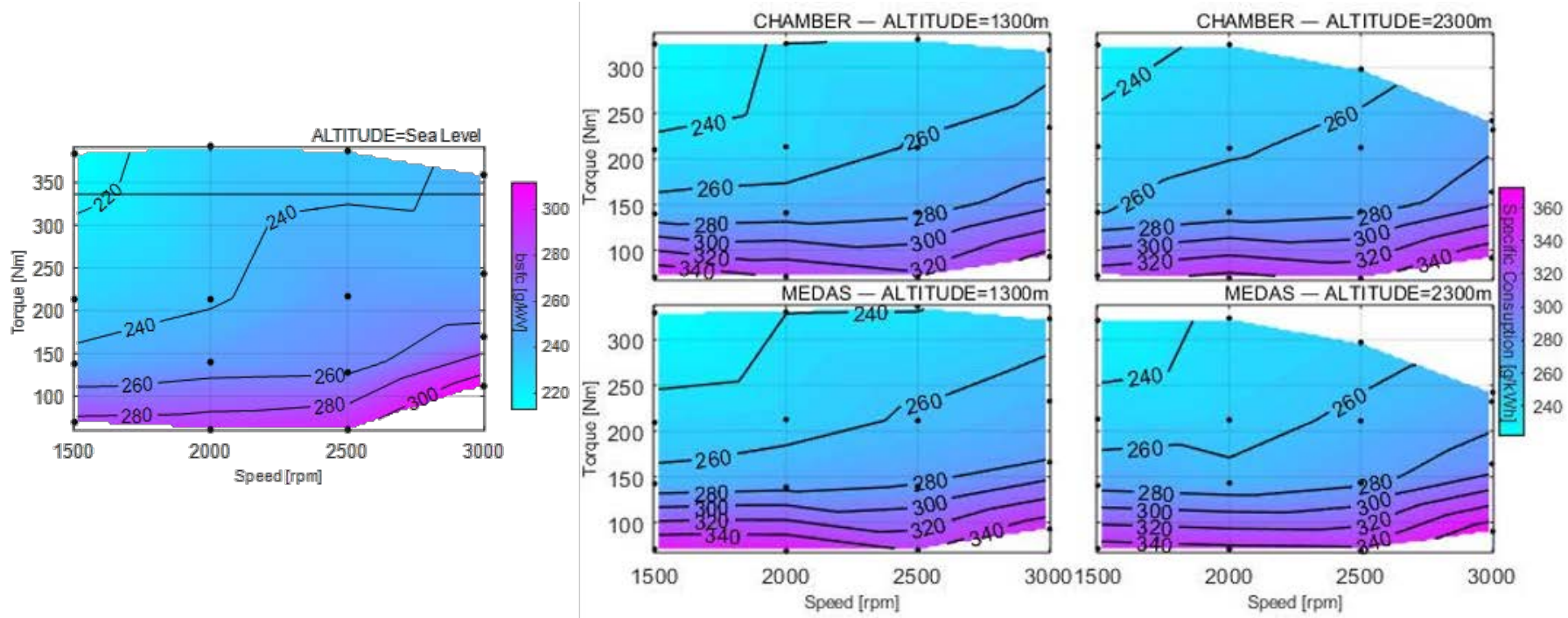

Fig. 11. Brake specific fuel consumptions (BSFC). Comparison of sea-level vs. altitude. Comparison of AS vs. hypobaric chamber. 

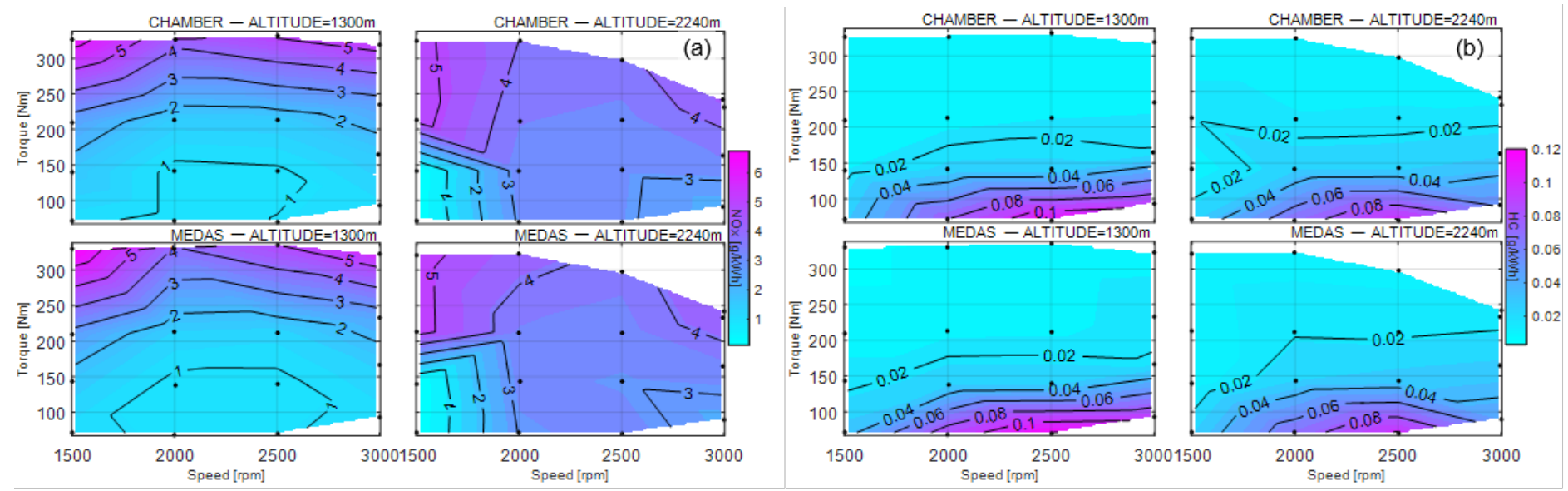

Fig. 12. Comparison of AS vs. hypobaric chamber. (a) NOx. (b) THC.

\section{SUMMARY AND CONCLUSIONS}

In this paper, on the one hand, the effects of the altitude over the performance and emissions of a turbocharged diesel engine had been discussed. On the other hand, the differences in the engine variables when tested inside a hypobaric chamber or connected to an altitude simulator has been assessed. This has been considered necessary since the altitude simulator (AS) only generates the vacuum inside the engine intake and exhaust ducts. In addition, the capacity of AS plus temperature and humidity modifiers (ASTM \& ASHM) to control the psychrometric variables independently, in both static and dynamic atmosphere simulation tests, has been also assessed.

With respect to altitude effects, it has been concluded that the performance of the turbocharged diesel engine is limited for protecting its components; mainly the turbo compressor, which approaches temperature, surge and over speed limits when increasing altitude. By these reasons the EGR has been avoided up to now as a generalized strategy. But this fact contributes to stress the turbine itself, whose inlet temperature limit is then more easily reached at high altitude.

With respect to emissions, the generation of pollutants is affected by the altitude; since EGR is limited or avoided and conditions at which combustion takes place change. For example, the air density, which affects the impingement in the walls and the penetration of the fuel spray, or the air to fuel ratio. Also the gas temperature at aftertreatment inlet (turbine outlet) is affected since the expansion ratio in the VGT is changing dramatically (generally increasing) as a function of altitude.

To compare the two altitude simulating technologies (hypobaric chamber and AS) a set of 16 steady state points, which cover a wide range of the engine map, have been tested at two different altitudes (1300 and 2300 meters). In conclusion, it has not been measured any significant difference between testing the engine in a full altitude environment and testing it connected to AS, nor in engine performance neither in emissions.

Finally, it has been also stated that, the emission measurement equipment can be used for taking samples from low pressure ducts and not significant differences between AS and hypobaric chamber have been found. The only precaution is choosing an emissions testing equipment with a pump powerful enough to pressurize the sample after sucking from vacuum.

\section{ACKNOWLEDGEMENTS}

This work was partially funded by FEDER and Government of Spain through Project TRA2016-79185-R

\section{NOMENCLATURE}

$\begin{array}{ll}\text { AS } & \text { Altitude Simulator } \\ \text { ASHM } & \text { Altitude Simulator Humidity Module } \\ \text { ASTM } & \text { Altitude Simulator Temperature Module } \\ \text { BMEP } & \text { Brake Mean Effective Pressure [bar] } \\ \text { BSFC } & \text { Brake Specific Fuel Consumption [gr/kWh] } \\ \text { DOC } & \text { Diesel Oxidation Catalyst } \\ \text { DPF } & \text { Diesel Particulate Filter } \\ \text { ECU } & \text { Engine Control Unit } \\ \text { EGR } & \text { Exhaust Gases Recirculation } \\ \text { MEDAS } & \text { Multifunctional Efficient and Dynamic } \\ \text { MHM } & \text { Altitude Simulator } \\ \text { MPD } & \text { MEDAS Humidity Module } \\ M T M & \text { Mean Percentage Dispersion } \\ N E D C & \text { MEDAS Temperature Module } \\ p 4 & \text { New European Driving Cycle } \\ \text { VGT } & \text { Turbine outlet pressure [bar] } \\ \text { WLTC } & \text { Variable Geometry Turbine } \\ & \text { World-wide Light duty Test Cycle }\end{array}$




\section{REFERENCES}

1. Regulation (EC) No 715/2007 of the European Parliament and of the Council, 20 June 2007.

2. ISO-2533:1975 (1975) Standard Atmosphere.

3. Hiroyasu H, Arai M, and Tabata M (1989) Empirical Equations for the Sauter Mean Diameter of a Diesel Spray. SAE Technical Paper, 890464.

4. Kihm K D, Terracina D P, Payne S E, and Caton J A (1994) Synchronized Droplet Size Measurements for Coal-Water Slurry Sprays Generated from a High-Pressure Diesel Injection System. Journal of the Institute of Energy, 67470, 2-9.

5. Zama Y, Ochiai W, Furuhata T, and Arai M (2011) Experimental study on spray angle and velocity distribution of diesel spray under high ambient pressure conditions. Atomization and Sprays, 2112, 989-1007.

6. Gómez, Javier. “Development of an altitude simulator and analysis of the performance and emissions of turbocharged Diesel engines at different altitudes." $\mathrm{PhD}$ Thesis. Universitat Politècnica de València. Valencia, Spain. 2018.

7. Toff W D, Jones C I, Ford I, Pearse R J, et al. (2006) Effect of Hypobaric Hypoxia, Simulating Conditions During Long-Haul Air Travel, on Coagulation, Fibrinolysis, Platelet Function, and Endothelial Activation. Jama, 29519, 2251.

8. Testa D, et al. (2011) Apparatus and method for altimetry conditioning of internal-combustion engines. European Patent Application No. 09425346.5 - EP2295955.

9. Desantes J.M.; Benajes J.; Bermúdez V.; Serrano J.R. et al “Device, method and use for conditioning intake air for testing internal combustion engines". PCT filling before the EPO No. PCT/EP2017/082452. Submission number: 5869232. Priority Date: December 12, 2017.

10. Payri F, Desantes J M, Galindo J, Serrano J R, et al. (2015) Device for conditioning the atmosphere in alternative internal combustion engine tests, procedure and use of said device. ES2544516B1 (P201530075) Spanish patent date 05/05/2016.

11. Payri F, Desantes J M, Galindo J, Serrano J R, et al. (2011) Unit for simulating the pressure and temperature conditions of the air drawn in by a reciprocating internal combustion engine. ES2398095B1 (P201130120) Spanish patent date 20/01/2014. PCT/ES2012/070010. USA Patent no 9038578. Japan Patent no 5788025. European Patent Application No. 12742066.9 EP2672248. Chinese Patent Application no 201280007012.6.

12. Bermúdez V, Serrano J R, Piqueras P, Gómez J, et al. (2017) Analysis of the role of altitude on diesel engine performance and emissions using an atmosphere simulator. International Journal of Engine Research, 18, 146808741667956.

13. Galindo J, Serrano J R, Piqueras P, and Gómez J (2014) Description and Performance Analysis of a Flow Test Rig to Simulate Altitude Pressure Variation for Internal Combustion Engines Testing. SAE International Journal of Engines, 74, 201401-2582.

14. Desantes J M, Payri F, Galindo J, Serrano J R, et al. (2014) Atmosphere conditioning device for testing of combustion engines, procedure and related use. ES2485618B1 (P201430071) Spanish patent date 25/03/2015. PCT WO2015110683A1. PCT/ES23015/070037.

15. Simperl J, et al. (2003) Method for supplying an internal combustion engine with conditioned combustion gas, device for carrying out said method, method for determining the quantities of pollutants in the exhaust gases of an internal combustion engine, and device for carrying out said method. MX PA03004561A. 